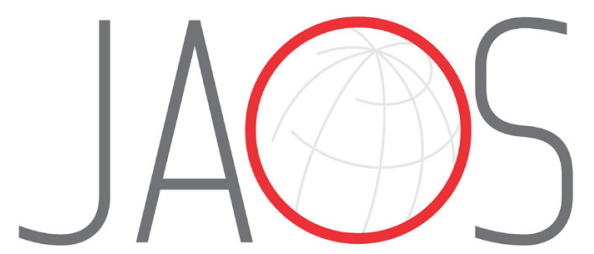

JOURNAL OF APPLIED ORAL SCIENCE

\title{
Analysis of permanent second molar development in children born with cleft lip and palate
}

\section{Abstract}

Manuella Santos Carneiro ALMEIDA ${ }^{1}$

Rosa Helena Wanderley LACERDA ${ }^{1}$ Karolline Batista LEAL ${ }^{2}$

Camila Helena Machado da Costa FIGUEIREDO ${ }^{2}$

Bianca Marques SANTIAGO ${ }^{1}$

Alexandre Rezende VIEIRA ${ }^{1,3}$
Submitted: October 24, 2019 Modification: March 21, 2020 Accepted: April 4, 2020

Corresponding address: Alexandre Rezende Vieira 335 - Sutherland Dr. Pittsburgh - PA 15261 United States of America. Phone: (412) 383-8972 Fax (412) 624-3080 e-mail: arv11@pitt.edu
The study of dental development in individuals born with cleft lip and palate (CLP) serves to determine when orthodontic intervention should start. Objective: To evaluate the permanent second molar development in children born with cleft lip and palate according to Demirjian's and Nolla's methods. Methodology: Out of a total of 513 digital panoramic radiographs, 113 pairs of children aged 3 to 16 years were selected. The exams were from children born with or without cleft lip and palate, of the same sex, with an age difference of up to 30 days. The images were analyzed by three examiners and reliability was checked through intra-examiner agreement by the Kappa test. The data were analyzed by Wilcoxon's and Mann-Whitney tests according to each dataset. Results: The findings indicated delayed development of the permanent second molars in children with CLP $(P<0.001)$. The development of the right permanent second molar was delayed compared to the left molar in children with CLP. Moreover, mandibular teeth showed significantly earlier development than maxillary teeth in both the case and control groups. There was no significant difference in the development of permanent second molars between sexes. Conclusion: Children with CLP presented delay in the development of permanent second molars.

Keywords: Cleft lip. Cleft palate. Dental Care. Diagnosis.
${ }^{1}$ Universidade Federal da Paraíba, João Pessoa, Paraíba, Brasil. ${ }^{2}$ Universidade Federal de Campina Grande, Patos, Paraíba, Brasil.

3University of Pittsburgh, Pittsburgh, Pennsylvania, United States of America. 


\section{Introduction}

Oral clefts are congenital malformations resulting from the non-closure of the frontonasal and maxillary processes during the first weeks of embryonic life. These conditions may manifest as an isolated phenomenon or in association with other congenital anomalies. ${ }^{1,2}$ Cleft lip associated or not with cleft palate, and cleft palate alone, are among the most common congenital malformations worldwide, affecting 1 in 700 newborns..$^{3-6}$ These birth defects have been attributed to genetic and environmental factors. ${ }^{7}$

Individuals with cleft lip and/or palate (CLP) experience significant impact in their quality of life. ${ }^{8,9}$ Morphological alterations resulting from these conditions may cause functional and esthetic issues, which, most often, lead to psychosocial distress. ${ }^{10}$ The extension and severity of the cleft will determine the nature of the issues, which generally include difficulty in breastfeeding, recurrent infections of the respiratory tract and middle ear, hearing and speech alterations, as well as occlusal and facial aesthetic problems. ${ }^{10,11}$

Orthodontic interventions are required for the rehabilitation of individuals with CLP. ${ }^{12}$ Nevertheless, very early orthodontic interventions should be avoided due to poor stability, which makes the rehabilitation process even more exhaustive for patients and their families. ${ }^{10}$ Several currently available methods can be used to determine the patient's age or maturity of the dentition, most frequently Nolla's ${ }^{13}$ (1960) and Demirjian's methods. ${ }^{14-16}$

Demirjian's method ${ }^{14}$ categorizes dental development into eight stages ( $\mathrm{A}$ to $\mathrm{H}$ ), as follows: $\mathrm{A}$ early calcification in the upper portion of the crypt, with cone or inverted cone shape and no fused calcification points; B - fusion of calcification points, cusp formation, occlusal surface delimitation; $\mathrm{C}$ - complete formation of the occlusal enamel, beginning of cervical extension, dentin deposition onto the upper portion, and early development of the pulp chamber contour; D - almost complete crown before the cemento-enamel junction is formed, well-defined pulp chamber ceiling; $\mathrm{E}$ - pulp chamber walls are better defined, root size smaller than crown height in posterior teeth, presence of pulp horns and onset of root bifurcation; $\mathrm{F}$ - pulp chamber walls forming an isosceles triangle, root size equal to or slightly larger than crown height; semilunar calcification in the furcation region of posterior teeth; wide conduits with beveled walls; G - parallel canal walls and partially open apex; $\mathrm{H}$ - apex closure.

Alternatively, Nolla ${ }^{13}$ (1960) proposed a dental development classification which includes 11 stages, namely: Stage 0: absence of crypt; Stage 1: formed crypt; Stage 2: Early mineralization; Stage 3: 1/3 formed crown; Stage 4: 2/3 crown mineralization; Stage 5: almost complete crown formation; Stage 6: fully mineralized crown; Stage 7: 1/3 formed root; Stage 8: 2/3 formed root; Stage 9: root almost formed, and open apex; Stage 10: formed root and closed apex.

The individual's chronological age is not always proportionally related to their stage of tooth development. ${ }^{17}$ Hence, we hypothesized that such differences may be even more apparent among children with CLP.

Some studies have evaluated the dental age of individuals with $\mathrm{CLP}^{12,18-23}$ but these studies do not focus on differences in side despite cleft lip and palate affecting the left lip two out of three instances. Our objective was to investigate the dental age of children born with CLP using Demirjian's and Nolla's methods, ${ }^{13,14}$ focusing on potential differences between cleft and non-cleft sides. Variations in tooth development between opposite sides in the dental arch have been reported in the literature. ${ }^{24-26}$ Thus, our study hypothesis was that there are significant arch side-related differences in tooth development in this group of patients.

\section{Methodology}

Five hundred and thirteen children treated at Cleft Lip and palate Center of Lauro Wanderley University Hospital (HULW), Federal University of Paraíba (UFPB), participated in this study. The inclusion criteria consisted of (i) children with CLP, (ii) aged 3 to 16 years, (iii) without any syndromes, systemic diseases or other orofacial clefts; (iv) of both sexes; (v) who had all permanent second molars (case group).

The sample size of the case group consisted of 113 digital panoramic radiographs. The distribution of cleft types is shown in Table 1. In addition, a total of 113 radiographs were selected for the control group from children without CLP with characteristics matching those of the case group regarding age (difference of up to 30 days) and sex. Children in the control group were excluded if they had any documented syndromes or systemic conditions. Participants who did not meet 
the eligibility criteria were excluded from the analysis.

The sample was composed of 56 (49.6\%) females and $57(50.4 \%)$ males. This study was previously approved by the Institutional Review Board under protocol CAAE 23683913.0.0000.5181.

Three previously calibrated examiners (M.S.C.A; R.H.W.L; C.H.M.C) carried out the analysis. Twenty panoramic radiographs were used for calibration, and as such were not included in the final sample. Calibration lasted two weeks and intra-examiner agreement was measured by the weighted Kappa coefficient (pondered Kappa>0.91).

Patient information was concealed from the panoramic radiographs to prevent bias. The calibrated examiners evaluated the radiographic images simultaneously for each method, and the stages of

Table 1- Analysis of cleft types according to sex

\begin{tabular}{lccccc}
\hline & \multicolumn{5}{c}{ Sex } \\
Cleft Type & \multicolumn{2}{c}{ Boys } & \multicolumn{2}{c}{ Girls } & Total \\
& Right & Left & Right & Left & N \\
\hline UCLP $^{1}$ & 8 & 21 & 7 & 25 & 61 \\
UCL $^{2}$ & - & 7 & 1 & 3 & 11 \\
BCLP $^{3}$ & 21 & & 15 & & 36 \\
BCL $^{4}$ & - & & - & & - \\
\hline CP $^{5}$ & - & & 5 & & 5 \\
\hline TOTAL & 57 & & 56 & & 113 \\
\hline
\end{tabular}

1- Unilateral cleft lip and palate

2- Unilateral cleft lip

3- Bilateral cleft lip and palate

4- Bilateral cleft lip

5- Cleft palate development of the second molars were chosen by consensus. The evaluations were carried out in a darkened room on a 23-inch screen using Windows Image Viewer and Fax Program ${ }^{\circledR}$ (Windows XP).

Each second molar (Upper right permanent second molar - UR7, Upper left permanent second molar - UL7, Lower left permanent second molar - LL7 and Lower right permanent second molar - LR7) was classified according to the stages proposed by Demirjian's and Nolla's methods. ${ }^{13,14}$

The stages of development of Demirjian's method ${ }^{14}$ were codified as follows: 1 for stage A, 2 for stage B, 3 for stage C, and so forth. Wilcoxon's test was used for inter-group comparisons. The differences between the groups (case and control) for the same method, between the arch sides for the same group, and between the methods, correspond to paired data, which justifies the use of the non-parametric paired Wilcoxon's test. Mann-Whitney's test, which is not a paired test, was used for comparison between sexes. The data were statistically analyzed in SPSS version 21.0 (Statistical Package for the Social Sciences) with a $5 \%$ margin of error.

\section{Results}

As shown in Table 2, the analysis of second molars by Demirjian's and Nolla's methods revealed higher percentages of advanced stages of development ( $F, G$,

Table 2- Analysis of the development stages of permanent second molars according to Demirjian's and Nolla's methods using Wilcoxon's test for paired data

\begin{tabular}{|c|c|c|c|c|c|c|c|}
\hline \multirow[b]{2}{*}{ Tooth } & \multicolumn{3}{|c|}{ Development } & \multicolumn{4}{|c|}{ Development } \\
\hline & stage & $\begin{array}{l}\text { With cleft lip } \\
\text { and palate }\end{array}$ & $\begin{array}{l}\text { Without cleft } \\
\text { lip and palate }\end{array}$ & stage & $\begin{array}{l}\text { With cleft lip } \\
\text { and palate }\end{array}$ & $\begin{array}{l}\text { Without cleft } \\
\text { lip and palate }\end{array}$ & P-value \\
\hline & Nolla & n (\%) & n (\%) & Demirjian & n (\%) & n (\%) & \\
\hline & 1 & - & - & A & $6(1.3)$ & $1(0.2)$ & $\mathrm{p}^{(1)<0.001^{*}}$ \\
\hline \multirow[t]{10}{*}{ (UR7,UL7, LL7, LR7) } & 2 & $6(1.3)$ & $1(0.2)$ & B & $2(0.4)$ & $7(1.5)$ & \\
\hline & 3 & $2(0.4)$ & $7(1.5)$ & C & $38(8.4)$ & $9(2.0)$ & \\
\hline & 4 & $33(7.3)$ & $9(2.0)$ & $\mathrm{D}$ & $98(21.7)$ & $49(10.8)$ & \\
\hline & 5 & $44(9.7)$ & $19(4.2)$ & $E$ & $140(31.0)$ & $134(29.6)$ & \\
\hline & 6 & $73(16.2)$ & $48(10.6)$ & $\mathrm{F}$ & $93(20.6)$ & $120(26.5)$ & \\
\hline & 7 & $126(27.9)$ & $116(25.7)$ & G & $37(8.2)$ & $57(12.6)$ & \\
\hline & 8 & $93(20.6)$ & $120(26.5)$ & $\mathrm{H}$ & $38(8.4)$ & $75(16.6)$ & \\
\hline & 9 & $37(8.2)$ & $57(12.6)$ & & & & \\
\hline & 10 & $38(8.4)$ & $75(16.6)$ & & & & \\
\hline & TOTAL & $452(100)$ & $452(100)$ & & $452(100)$ & $452(100)$ & \\
\hline
\end{tabular}

$\left({ }^{*}\right)$ : Significant difference at $5.0 \%$.

$(\dagger)$ : By the Wilcoxon's test for paired data. 
$\mathrm{H}$ for Demirjian's method and 8, 9 and 10 for Nolla's method) among individuals without CLP $(P<0.001)$. Moreover, Table 3 shows differences in the development of each permanent second molar between individuals with and without CLP and tooth development was found to be more delayed among individuals with CLP (case group), regardless of the tooth $(P<0.05)$.

Out of a total of 113 individuals with CLP, 13 showed different stages of development between the left and right arch sides, regardless of the cleft side. A relationship between the type and side of the cleft and the occurrence of delayed development of the second molars was investigated here. In individuals with left-UCLP, there was a greater frequency of delayed development on the right side, that is, on the noncleft side (Fisher's Exact test, $P=0.05$ ). As for those with right-UCLP, only one case showed delayed molar development, which occurred on the cleft side.
The frequency of delay in second molar development among individuals with bilateral clefts was compared against that of the control group. The findings indicated that bilateral clefts were significantly associated with delayed second molar development (Fisher's Exact test, $P=0.01)$. Six out of 36 BCLP cases showed delayed development of at least one second molar, while only 5 out of 113 control cases showed delayed second molar development. No significant arch siderelated differences in second molar development were observed.

As seen in Table 4, Demirjian's method revealed significant differences in the development of maxillary and mandibular second molars, with correspondingly greater development in the mandibular ones $(P<0.05)$. Demirjian's (but not Nolla's) method revealed differences between maxillary and mandibular tooth development in both the case and control groups.

Table 3- Analysis of the development stages of permanent second molars in individuals with or without cleft lip and palate, according to the classification method, using Wilcoxon's test for paired data

\begin{tabular}{|c|c|c|c|c|}
\hline \multirow[b]{2}{*}{ Tooth } & \multicolumn{4}{|c|}{ Group } \\
\hline & Development & With cleft lip and palate & Without cleft lip and palate & $P$-value \\
\hline & method & Median (P25;P75) & Median (P25;P75) & \\
\hline \multirow[t]{2}{*}{ UR7 } & Demirjian & $5.00(4.00 ; 5.00)$ & $6.00(5.00 ; 7.00)$ & $\mathrm{p}^{(1)<0.001^{*}}$ \\
\hline & Nolla & $7.00(6.00 ; 8.00)$ & $8.00(7.00 ; 9.00)$ & $\mathrm{p}^{(1)<0.001^{*}}$ \\
\hline \multirow[t]{2}{*}{ UL7 } & Demirjian & $5.00(4.00 ; 6.00)$ & $6.00(5.00 ; 7.00)$ & $\mathrm{p}^{(1)<0.001^{*}}$ \\
\hline & Nolla & $7.00(6.00 ; 8.00)$ & $8.00(7.00 ; 9.00)$ & $\mathrm{p}^{(1)<0.001^{*}}$ \\
\hline \multirow[t]{2}{*}{ LL7 } & Demirjian & $5.00(4.00 ; 6.00)$ & $6.00(5.00 ; 7.00)$ & $\mathrm{p}^{(1)<0.001^{*}}$ \\
\hline & Nolla & $7.00(6.00 ; 8.00)$ & $8.00(7.00 ; 9.00)$ & $\mathrm{p}^{(1)}<0.001^{*}$ \\
\hline \multirow[t]{2}{*}{ LR7 } & Demirjian & $5.00(4.00 ; 6.00)$ & $6.00(5.00 ; 7.00)$ & $\mathrm{p}^{(1)<0.001^{*}}$ \\
\hline & Nolla & $6.00(7.00 ; 8.00)$ & $8.00(7.00 ; 9.00)$ & $\mathrm{p}^{(1)<0.001^{*}}$ \\
\hline
\end{tabular}

$\left.{ }^{*}\right)$ : Significant difference at $5.0 \%$.

$(\dagger)$ : By Wilcoxon's test for paired data.

Table 4- Analysis of the development stages of permanent second molars in individuals with or without cleft lip and palate, according to arch (maxilla or mandible), using Wilcoxon's test for paired data

\begin{tabular}{|c|c|c|c|c|}
\hline \multirow[b]{2}{*}{ Group of teeth } & \multicolumn{4}{|c|}{ Group } \\
\hline & Method/Arch & With cleft lip and palate & Without cleft lip and palate & $P$-value \\
\hline & & Median (P25;P75) & Median (P25;P75) & \\
\hline \multirow[t]{8}{*}{ Second molars } & Demirjian & & & \\
\hline & Upper & $5.00(4.00 ; 6.00)$ & $6.00(5.00 ; 7.00)$ & $\mathrm{p}^{(1)<0.001^{*}}$ \\
\hline & Lower & $5.00(4.00 ; 6.00)$ & $6.00(5.00 ; 7.00)$ & $\mathrm{p}^{(1)<0.001^{*}}$ \\
\hline & $P$-value & $\mathrm{p}^{(2)}=0.008^{*}$ & $\mathrm{p}^{(2)}=0.005^{*}$ & \\
\hline & Nolla & & & \\
\hline & Upper & $7.00(6.00 ; 8.00)$ & $8.00(7.00 ; 9.00)$ & $\mathrm{p}^{(1)<0.001^{*}}$ \\
\hline & Lower & $7.00(6.00 ; 8.00)$ & $8.00(7.00 ; 9.00)$ & $\mathrm{p}^{(1)<0.001^{*}}$ \\
\hline & $P$-value & $\mathrm{p}^{(2)}=0.262$ & $\mathrm{p}^{(2)}=0.052$ & \\
\hline
\end{tabular}

$\left.{ }^{*}\right)$ : Significant difference at $5.0 \%$.

$(\dagger)$ : Using Wilcoxon's test for paired data for the comparison between the second molar teeth in each arch.

$(\ddagger)$ : Using Wilcoxon's test for paired data for the comparison between arches. 
Table 5- Analysis of permanent second molar development according to sex using the Mann-Whitney's test

\begin{tabular}{ccccc}
\hline Sex & \multicolumn{2}{c}{ Dermijian method } & \multicolumn{2}{c}{ Nolla method } \\
& With cleft lip and palate & Without cleft lip and palate & With cleft lip and palate & Without cleft lip and palate \\
& Median (P25; P75) & Median (P25; P75) & Median (P25; P75) & Median (P25; P75) \\
\hline Male & $5.00(4.00 ; 6.00)$ & $6.00(5.00 ; 6.00)$ & $7.00(6.00 ; 8.00)$ & $8.00(7.00 ; 8.00)$ \\
Female & $5.00(4.00 ; 6.00)$ & $6.00(5.00 ; 7.00)$ & $7.00(6.00 ; 8.00)$ & $8.00(7.00 ; 9.00)$ \\
Value of $p$ & $\mathrm{P}^{(1)}=0.396$ & $\mathrm{P}^{(1)}=0.091$ & $\mathrm{P}^{(1)}=0.168$ & $\mathrm{P}^{(1)}=0.087$ \\
\hline
\end{tabular}

$\left({ }^{*}\right)$ : Significant difference at $5.0 \%$.

(1): Using Mann-Whitney's test for the comparison between sexes in each group.

Table 5 shows no significant differences in the development of permanent second molars between sexes $(P>0.05)$.

\section{Discussion}

Demirjian's method ${ }^{14}$ categorizes dental development into eight stages, whereas Nolla's method $^{13}$ includes 11 stages of development. As these methods use different analytical scores, it is impracticable to make a direct, inferential comparison between them other than a descriptive analysis. The advantage of using internationally validated methods is the possibility of comparing the findings across different populations and ethnicities. Demirjian's and Nolla's methods ${ }^{13,14}$ were chosen in our study for their broad applicability worldwide. ${ }^{12,15,16,18-24,26}$

While children with CLP are known to have normal genetic potential for growth, ${ }^{27,28}$ some studies have demonstrated that they may present a delay in dental maturation. 19,20,24 The development of permanent dentition takes longer in children with CLP than otherwise and may be increased depending on the severity of the cleft. ${ }^{22}$ In addition, eruption of the permanent teeth is slower on the side of the cleft. ${ }^{29}$ Consistent with this, both methods in our study demonstrated a delay in the development of the permanent second molars in individuals with CLP, regardless of the cleft side, compared to those without any clefts.

Nolla $^{13}$ (1960) and Dhanjal, et al. ${ }^{30}$ (2006) reported no significant differences in tooth mineralization in patients without malformation in the maxillomandibular complex, regardless of the arch side. Ribeiro, et al. ${ }^{31}$ (2002) and Pioto, Costa, Gomide ${ }^{32}$ (2005) compared the dental development of the maxillary lateral incisor in the region of the cleft with the development of its counterpart tooth in individuals with unilateral CLP. The authors observed a delay in tooth development on the cleft side. In our study, significant differences between the right and left sides were observed regarding the development of the second molar. Individuals with left-UCLP showed a greater frequency of delayed tooth development on the right side, that is, on the noncleft side. Evidence suggests that during craniofacial development, some genes expressed on the left side are absent on the right side, ${ }^{33}$ which is likely not due to chance alone.

Dhanjal, et al. ${ }^{30}$ (2006) and Orhan, et al. ${ }^{34}$ (2007) reported that mandibular teeth were considerably more developed than maxillary ones, similarly to what was observed in our study when using Demirjian's method. ${ }^{14}$ In contrast, similar tooth development was observed between the maxillary and mandibular arches when Nolla's ${ }^{13}$ method was used. It is worth noting that both methods differ in terms of graphical illustrations and codes for differentiation of the tooth development stages, as Nolla's method ${ }^{13}$ considers 11 stages while Demirjian's method ${ }^{14}$ consists of 8 stages. Hence, the differences observed between methods may be explained by the larger number of stages of development considered by Nolla ${ }^{13}$ (1960). It can be considered more effective in characterizing the stages of tooth development than Demirjian's method ${ }^{14}$ and thereby reduce sharp variations taking place in between each stage.

Both methods are based on the evaluation of the seven left mandibular permanent teeth for estimating dental age, except for the third molar. Originally, the stages of development in both methods should be converted into values whose sum would indicate the dental age according to tables developed by the authors. However, the analysis of the mandibular left hemiarch alone does not consider comprehensive patient information such as a general overview of the patient's dental development in each arch side. Moreover, the analysis of a single mouth quadrant may overlook important parameters, for instance, tooth development in the other three quadrants, arch side- 
related differences in tooth development, as well as the association between delayed tooth development, the type of cleft, and the non-cleft side. Thus, in our study, we considered only the graphical illustrations and tooth development codes from Nolla's and Demirjian's methods ${ }^{13,14}$ and analyzed the permanent second molars of each mouth quadrant.

Our findings showed no significant difference in tooth development between the sexes $(P=0.396$, $P=0.168$ - case group; $P=0.091, P=0.087$ - control group for Demirjian and Nolla Method, respectively). These results disagree with previously published studies, ${ }^{35-38}$ where females were found to have earlier tooth development than males. ${ }^{36,38}$ Intriguingly, Soares, et al. ${ }^{35}$ (2015) and Ribeiro, et al. ${ }^{37}$ (2018) observed earlier apical closure in males.

Heterogeneous distribution of cleft types was present in our study sample, which included unilateral and bilateral CLP, unilateral cleft lip and cleft palate. Herein, there were no children with bilateral cleft lip in the sample, hence further research addressing tooth development should consider a broader spectrum of cleft types. Moreover, due to the limited number of individuals with CLP in the sample, subjects were not excluded based on ethnicity. As this was a matchedcontrol study, any ethnic differences that could potentially induce bias were eliminated through the sample matching process.

The determination of the most suitable time to start treatment depends directly on the stage of dental maturity. Very early orthodontic interventions are discouraged because of the high probability of relapse in the long term. ${ }^{10}$ Hence, establishing the treatment start date is a critical aspect of the rehabilitation process, as individuals with CLP experience a long and complex rehabilitation history.

Taken altogether, our study reinforces the importance of conducting orthodontic planning based on the individuality of each patient and their CLP characteristics. Choosing the most appropriate moment to intervene not only renders treatment more effective but also contributes to the social and psychological compliance of cleft patients. The management of patients with clefts should comprehend humanized contact with them and include therapeutic options that require less exposure to inappropriate or untimely procedures.

\section{Conclusions}

The dental development of permanent second molars by Demirjian's and Nolla's methods ${ }^{13,14}$ is delayed in children born with cleft lip and palate.

Arch side-related differences in tooth development were observed in individuals with unilateral left cleft lip and palate, with delay most often observed on the right side, that is, on the non-cleft side.

Demirjian's (but not Nolla's) method revealed differences between maxillary and mandibular tooth development in both the case and control groups, but no differences were observed between sexes.

\section{Acknowlegments}

The authors are indebted to the participants of the study and the Smile Train for the support of the treatment of cleft lip and palate individuals.

\section{Declaration of conflicting interests}

The author(s) declare no potential conflicts of interest with respect to the study, authorship, and/or publication of this article.

\section{Funding}

The author(s) received no financial support for the study, authorship, and/or publication of this article.

\section{Authors' contributions}

Almeida, M. S. C.: Conceptualization (Lead), Data curation (Lead), Investigation (Equal), Methodology (Equal), Resources (Equal), Writingoriginal draft (Equal); Lacerda, R. H. W.: Data curation (Equal), Supervision (Equal), Writing-original draft (Supporting); Leal, K. B.: Conceptualization (Supporting), Data curation (Equal), Investigation (Supporting), Methodology (Supporting), Writingoriginal draft (Equal); Figueiredo, C. H. M. C.: Data curation (Equal), Investigation (Equal), Methodology (Equal), Supervision (Equal); Santiago, B.: Project administration (Equal), Supervision (Equal), Writingreview \& editing (Equal); Vieira, A. R.: Project administration (Equal), Supervision (Equal), Writingoriginal draft (Equal), Writing-review \& editing (Equal) 


\section{References}

1- Nunes LM, Queluz DP, Pereira AC. Prevalence of oral cleft in Campos dos Goytacazes-RJ, 1999-2004. Rev Bras Epidemiol. 2007;10:109-16. 2- Sabóia TM, Küchler EC, Tannure PN, Rey AC, Granjeiro JM, Castro Costa $M$, et al. Mesio-distal and buccal-lingual tooth dimensions are part of the cleft spectrum: a pilot for future genetic studies. Cleft Palate Craniofac J. 2013;50:678-83. doi: 10.1597/11-228. doi: 10.1597/11-228

3- Matern O, Sauleau EA, Tschill P, Perrin-Schmitt F, Grollemund B. Left-sided predominance of hypodontia irrespective of cleft sidedness in a French population. Cleft Palate Craniofac J. 2012;49:1-5. doi: 10.1597/11-025

4- Antunes LS, Küchler EC, Tannure PN, Costa MC, Gouvêa CV, Olej $B$, et al. BMP4 polymorphism is associated with non-syndromic oral cleft in a Brazilian population. Cleft Palate Craniofac J. 2013;50:633-8. doi: $10.1597 / 12-04$

5- Paranaiba LM, Coletta RD, Swerts MS, Quintino RP, Barros LM, MartelliJúnior $\mathrm{H}$. Prevalence of dental anomalies in patients with nonsyndromic cleft lip and/or palate in a Brazilian population. Cleft Palate Craniofac J. 2013;50:400-5. doi: 10.1597/11-029

6- Pavri S, Forrest CR. Demographics of orofacial clefts in Canada from 2002 to 2008. Cleft Palate Craniofac J. 2013;50:224-30. doi: $10.1597 / 10-223$

7- Batista LR, Triches TC, Moreira EA. Oral development and breastfeeding in children with cleft lip and palate. Rev Paul Pediatr. 2011;29:674-9.

8- Wu J, Zheng Q, Huang YQ, Wang Y, Li S, Lu DW, et al. Significant evidence of association between polymorphisms in ZNF533, environmental factors, and nonsyndromic orofacial clefts in the Western Han Chinese population. DNA Cell Biol. 2011;30:47-54. doi: 10.1089/ dna.2010.1082

9- Shaikh S, Ravenndranath R, Banerjee M, Joseph A, Jahgirdar P. Evidence for transforming growth factor-beta 3 gene polymorphism in non-syndromic cleft lip and palate patients from Indian subcontinent. Med Oral Patol Oral Cir Bucal. 2012;17:197-200. doi: 10.4317/medoral.17453

10- Freitas JA, Garib DG, Oliveira TM, Lauris RC, Almeida AL, Neves LT, et al. Rehabilitative treatment of cleft lip and palate: experience of the Hospital for Rehabilitation of Craniofacial Anomalies-USP (HRACUSP) - Part 2: overall aspects. J Appl Oral Sci. 2012;20:268-81. doi: 10.1590/s1678-77572012000200024

11- Freitas JA, Neves LT, Almeida AL, Garib DG, Suedam IK, Yaedú RY, et al. Rehabilitative treatment of cleft lip and palate: experience of the Hospital for Rehabilitation of Craniofacial Anomalies-USP (HRAC-USP) - Part 1: overall aspects. J Appl Oral Sci. 2012;20:9-15. doi: 10.1590/ s1678-77572012000100003

12- Topolski F, Souza RB, Franco A, Cuoghi OA, Assunção LR, Fernandes A. Dental development of children and adolescents with cleft lip and palate. Braz J Oral Sci. 2014;13:319-24.

13- Nolla CM. The development of permanent teeth. J Dent Child.1960;4:254-66.

14- Demirjian A, Goldstein H, Tanner JM. A new system of dental age assessment. Human Biol. 1973;45:211-27.

15- Diz P, Limeres J, Salgado AF, Tomás I, Delgado LF, Vázquez E, et al. Correlation between dental maturation and chronological age in patients with cerebral palsy, mental retardation and Down syndrome. Res Develop Disab. 2011;32:808-17. doi: 10.1016/j.ridd.2010.10.01 16- Yan J, Lou X, Xie L, Yu D, Shen G, Wang Y. Assessment of dental age of children aged 3.5 to 16.9 years using Demirjian's method: a meta-analysis based on 26 studies. PloS One. 2013;8:846-72. doi: $10.1371 /$ journal.pone.0084672
17- Almeida MS, Pontual AD, Beltrão RT, Beltrão RV, Pontual ML. The chronology of second molar development in Brazilians and its application to forensic age estimation. Imaging Sci Dent. 2013;43:1-6. doi: 10.5624/isd.2013.43.1.1

18- Mitsea AG, Spyropoulus MN. Premolar development in Greek children with cleft lip and palate. Quintessence Int. 2001;32:639-46. 19- Heidbüchel KL, Kuijpers-Jagtman AM, Ophof R, Van Hooft RJ. Dental maturity in children with a complete bilateral cleft lip and palate. Cleft Palate Craniofac J. 2002;39:509-12. doi: 10.1597/15451569_2002_039_0509_dmicwa_2.0.c0_2

20- Huyskens RW, Katsaros C, Van't Hof MA, Kuijpers-Jagtman AM. Dental age in children with a complete unilateral cleft lip and palate. Cleft Palate Craniofac J. 2006;43:612-5. doi: 10.1597/05-096 21- Borodkin AF, Feigal RJ, Beiraghi S, Moller KT, Hodges JS. Permanent tooth development in children with cleft lip and palate. Pediatr Dent. 2008;30:408-13.

22- Hazza'a AM, Rawashdeh MA, Al-Jamal G, Al-Nimri KS. Dental development in children with cleft lip and palate: a comparison between unilateral and bilateral clefts. Eur J Paediatr Dent. 2009;10:90-4.

23- Almotairy A, Pegelow M. Dental age comparison in patients born with unilateral cleft lip and palate to a control sample using Demirjian and Willems methods. Eur J Orthod. 2017;40(1):74-81. doi: 10.1093/ ejo/cjx031

24- Lai MC, King NM, Wong HM. Dental development of Chinese children with cleft lip and palate. Cleft Palate Craniofac J. 2008;45:289-96. doi: 10.1597/07-019

25- Zhang X, Zhang Y, Yang L, Shen G, Chen Z. Asymmetric dental development investigated by cone-beam computed tomography in patients with unilateral cleft lip and alveolus. Cleft Palate Craniofac J. 2016;53:413-20. doi: 10.1597/15-077

26- Tan EL, Kuek MC, Wong HC, Yow M. Longitudinal dental maturation of children with complete unilateral cleft lip and palate: a case-control cohort study. Orthod Craniofac Res. 2017;20(4)189-95. doi: 10.1111/ ocr.1219

27- Pruzanski S. Factors determining form in cleft of the lip and palate. Am J Orthod. 1955;41:827-51.

28- ALBarakati SF, Alkofide EA. Growth status of Saudi patients with cleft lip and palate. Saudi Med J. 2002;23:823-7.

29- Ranta R. A review of tooth formation in cleft lip/palate. Am J Orthod Dentofacial Orthop. 1986;90:11-8. doi: 10.1016/08895406(86)90022-3

30- Dhanjal KS, Bhardwaj MK, Liversidge HM. Reproducibility of radiographic stage assessment of third molars. Forensic Sci Int. 2006;159(Suppl):74-7. doi: 10.1016/j.forsciint.2006.02.020 31- Ribeiro LL, Teixeira das Neves L, Costa B, Gomide MR. Dental development of permanent lateral incisor in complete unilateral cleft lip and palate. Cleft Palate Craniofac J. 2002;39(2):193-6. doi: 10.1597/1545-1569_2002_039_0193_ddopli_2.0.co_2

32- Pioto NR, Costa B, Gomide MR. Dental development of the permanent lateral incisor in patients with incomplete and complete unilateral cleft lip. Cleft Palate Craniofac J. 2005;42:517-20. doi: 10.1597/04-045r.1

33- Boorman CJ, Shimeld SM. The evolution of left-right asymmetry in chordates. Bioessays. 2002;24:1004-11. doi: 10.1002/bies.10171 34- Orhan K, Ozer L, Orhan A I, Dogan S, Paksoy CS. Radiographic evaluation of third molar development in relation to chronological age among Turkish children an youth. Forensic Sci Int. 2007;165:46-51. doi: $10.1016 /$ j.forsciint.2006.02.046

35- Soares CB, Figueiroa JN, Dantas RM, Kurita LM, Pontual AA, Ramos-Perez FM, et al. Evaluation of third molar development in the estimation of chronological age. Forensic Sci Int. 2015;254:13-7. DOI: 10.1016/j.forsciint.2015.06.022 
36- Hofmann E, Robold M, Proff P, Kirschneck C. Age assessment based on third molar mineralisation: an epidemiological-radiological study on a Central-European population. J Orofac Orthop. 2017;78:97-111. doi: 10.1007/s00056-016-0063-z

37- Ribeiro EC, Sousa LF Filho, Camelo CA, Araújo JC Filho, Guaré RO, Costa $\mathrm{CH}$, et al. Correlation between third molar mineralization and chronological age by three methods. Rev Cub Estomatol. 2018;55:1-11.
38- Jung $\mathrm{YH}, \mathrm{Cho} \mathrm{BH}$. Radiographic evaluation of third molar development in 6- to 24-year-olds. Imaging Sci Dent. 2014;44:18591. doi: $10.5624 /$ isd.2014.44.3.185 